\title{
(2) OPEN ACCESS \\ End-tidal and arterial carbon dioxide gradient in serious traumatic brain injury after prehospital emergency anaesthesia: a retrospective observational study
}

\author{
James Price (1) , ${ }^{1,2}$ Daniel D Sandbach, ${ }^{1}$ Ari Ercole ㅈ , ${ }^{1,3}$ Alastair Wilson, ${ }^{1,4}$ \\ Ed Benjamin Graham Barnard (1) 1,2,5
}

\section{Handling editor Ellen J Weber \\ ${ }^{1}$ Department of Research, Audit, Innovation, \& Development (RAID), East Anglian Air Ambulance, Norwich, UK 2Emergency Department, Addenbrooke's Hospital, Cambridge, UK ${ }^{3}$ University of Cambridge Division of Anaesthesia, Addenbrooke's Hospital, Cambridge, UK \\ ${ }^{4}$ Emergency Department (Retired), Royal London Hospital, London, UK \\ ${ }^{5}$ Academic Department of Military Emergency Medicine, Royal Centre for Defence Medicine (Research \& Academia), Birmingham, UK}

\section{Correspondence to} James Price, Department of Research, Audit, Innovation, \& Development (RAID), East Anglian Air Ambulance, Norwich, UK james.price@eaaa.org.uk

Received 3 September 2019 Revised 8 July 2020 Accepted 13 August 2020 Published Online First 14 September 2020

Check for updates

(C) Author(s) (or their employer(s)) 2020. Re-use permitted under CC BY-NC. No commercial re-use. See rights and permissions. Published by BMJ.

To cite: Price J,

Sandbach DD, Ercole A,

et al. Emerg Med J

2020:37:674-679.

\section{ABSTRACT}

Objectives In the UK, $20 \%$ of patients with severe traumatic brain injury (TBI) receive prehospital emergency anaesthesia (PHEA). Current guidance recommends an end-tidal carbon dioxide (ETCO $)$ of 4.0-4.5 kPa (30.0 $33.8 \mathrm{~mm} \mathrm{Hg}$ ) to achieve a low-normal arterial partial pressure of $\mathrm{CO}_{2}\left(\mathrm{PaCO}_{2}\right)$, and reduce secondary brain injury. This recommendation assumes a $0.5 \mathrm{kPa}(3.8 \mathrm{~mm}$ $\mathrm{Hg}) \mathrm{ETCO}_{2}-\mathrm{PaCO}_{2}$ gradient. However, the gradient in the acute phase of $\mathrm{TBI}$ is unknown. The primary aim was to report the $\mathrm{ETCO}_{2}-\mathrm{PaCO}_{2}$ gradient of $\mathrm{TBI}$ patients at hospital arrival.

Methods A retrospective cohort study of adult patients with serious TBI, who received a PHEA by a prehospital critical care team in the East of England between 1 April 2015 and 31 December 2017. Linear regression was performed to test for correlation and reported as R-squared $\left(R^{2}\right)$. A Bland-Altman plot was used to test for paired $\mathrm{ETCO}_{2}$ and $\mathrm{PaCO}_{2}$ agreement and reported with $95 \% \mathrm{Cl}$. ETCO $-\mathrm{PaCO}_{2}$ gradient data were compared with a two-tailed, unpaired, t-test.

Results 107 patients were eligible for inclusion. Sixtyseven patients did not receive a $\mathrm{PaCO}_{2}$ sample within 30 min of hospital arrival and were therefore excluded. Forty patients had complete data and were included in the final analysis; per protocol. The mean $\mathrm{ETCO}_{2}-\mathrm{PaCO}_{2}$ gradient was $1.7( \pm 1.0) \mathrm{kPa}(12.8 \mathrm{~mm} \mathrm{Hg})$, with moderate correlation $\left(R^{2}=0.23, p=0.002\right)$. The Bland Altman bias was $1.7(95 \% \mathrm{Cl} 1.4$ to 2.0$) \mathrm{kPa}$ with upper and lower limits of agreement of $3.6(95 \% \mathrm{Cl} 3.0$ to 4.1) $\mathrm{kPa}$ and $-0.2(95 \% \mathrm{Cl}-0.8$ to 0.3$) \mathrm{kPa}$, respectively. There was no evidence of a larger gradient in more severe TBI $(p=0.29)$. There was no significant gradient correlation in patients with a coexisting serious thoracic injury $\left(R^{2}=0.13, p=0.10\right)$, and this cohort had a larger ETCO $-P_{2}$ aCO gradient, $2.0( \pm 1.1) \mathrm{kPa}(15.1 \mathrm{~mm} \mathrm{Hg})$, $p=0.01$. Patients who underwent prehospital arterial blood sampling had an arrival $\mathrm{PaCO}_{2}$ of $4.7( \pm 0.2) \mathrm{kPa}$ (35.1 $\mathrm{mm} \mathrm{Hg}$ ).

Conclusion There is only moderate correlation of $\mathrm{ETCO}_{2}$ and $\mathrm{PaCO}_{2}$ at hospital arrival in patients with serious TBI. The mean $\mathrm{ETCO}_{2}-\mathrm{PaCO}_{2}$ gradient was 1.7 $( \pm 1.0) \mathrm{kPa}(12.8 \mathrm{~mm} \mathrm{Hg})$. Lower ETCO, targets than previously recommended may be safe and appropriate, and there may be a role for prehospital $\mathrm{PaCO}_{2}$ measurement.

\section{Key messages}

What is already known on this subject

- The optimal management of ventilation in patients with serious traumatic brain injury (TBI) reduces secondary brain insult.

- Current guidance recommends the use of end-tidal carbon dioxide $\left(\mathrm{ETCO}_{2}\right)$ as a surrogate for arterial carbon dioxide $\left(\mathrm{PaCO}_{2}\right)$ to guide ventilation strategy in the prehospital environment.

- The effect of the $\mathrm{ETCO}_{2}-\mathrm{PaCO}_{2}$ gradient on resultant $\mathrm{PaCO}_{2}$ early in this disease process is unknown.

What this study adds

- This retrospective cohort study of 40 patients receiving prehospital emergency anaesthesia found only moderate correlation of ETCO, and $\mathrm{PaCO}_{2}$ in patients with serious TBI, thus the use of $\mathrm{ETCO}_{2}$ to guide ventilation is a blunt tool in this cohort.

- The $\mathrm{ETCO}_{2}-\mathrm{PaCO}_{2}$ gradient is larger than previously reported and is increased by the presence of coexisting thoracic injuries. Prehospital $\mathrm{PaCO}_{2}$ measurement resulted in more accurate titration of ventilatory strategy.

\section{BACKGROUND}

Traumatic brain injury (TBI) is the leading cause of death and disability following trauma, with 69 million estimated new cases each year worldwide. ${ }^{1}$ Optimising cerebral blood flow $(\mathrm{CBF})$ is the mainstay of treatment to prevent secondary brain injury and reduce mortality. ${ }^{2}$ Early management of raised intracranial pressure (ICP) includes controlled ventilation via prehospital emergency anaesthesia (PHEA). ${ }^{3}$ A growing number of emergency medical services are providing this. ${ }^{4}$ At present, it is estimated that one in five patients with severe TBI undergo PHEA. ${ }^{5}$

The use of end-tidal capnography to confirm endotracheal tube position is widely accepted. ${ }^{6}$ Current guidance encourages the use of end-tidal carbon dioxide $\left(\mathrm{ETCO}_{2}\right)$ as a surrogate for the arterial partial pressure of carbon dioxide $\left(\mathrm{PaCO}_{2}\right)$ to guide ventilation. ${ }^{78}$ Under normal physiological 
conditions, alveolar dead space accounts for a $0.5 \mathrm{kPa}(3.8 \mathrm{~mm}$ $\mathrm{Hg}) \mathrm{ETCO}_{2}-\mathrm{PaCO}_{2}$ gradient in ventilated patients. ${ }^{9}$ In-hospital data demonstrate good correlation in patients with TBI. ${ }^{10-12}$ The Association of Anaesthetists recommend an $\mathrm{ETCO}_{2}$ target of $4.0-4.5 \mathrm{kPa}(30.0-33.8 \mathrm{~mm} \mathrm{Hg})$ to achieve normocapnia.?

The mechanisms of autoregulation of CBF differ with changes in ICP. ${ }^{13}$ Respiratory dysfunction and loss of autoregulation is common in patients with TBI, ${ }^{14}$ and a $1 \%$ change in $\mathrm{PaCO}_{2}$ can lead to changes of up to $4 \%$ in CBF. ${ }^{15}$ Prehospital data evaluating the use of $\mathrm{ETCO}_{2}$ are limited, but are not consistent with in-hospital findings; leading to some criticism of the use of $\mathrm{ETCO}_{2}$ to guide ventilation. ${ }^{16-18}$ In most cases of TBI, an increase in ICP evolves over hours, and therefore moderate hypercapnia prehospital would be expected to increase CBF. However, the effect of the $\mathrm{ETCO}_{2}-\mathrm{PaCO}_{2}$ gradient on resultant $\mathrm{PaCO}_{2}$ early in this disease process is unknown. The primary objective of this study was to report the $\mathrm{ETCO}_{2}-\mathrm{PaCO}_{2}$ gradient at hospital arrival in a cohort of patients with serious TBI who underwent PHEA.

\section{Hypothesis}

Patients with serious TBI who undergo PHEA have an $\mathrm{ETCO}_{2}-$ $\mathrm{PaCO}_{2}$ gradient greater than $0.5 \mathrm{kPa}(3.8 \mathrm{~mm} \mathrm{Hg})$.

\section{METHODS}

In this retrospective observational study, a convenience sample of patients who underwent PHEA by a single UK prehospital team (East Anglian Air Ambulance, EAAA) between 1 April 2015 and 31 December 2017 was extracted from the EAAA electronic medical record.

\section{Prehospital critical care team}

EAAA is a medical charity that provides prehospital critical care to the statutory ambulance service in the East of England (East of England Ambulance Service NHS Trust). EAAA operates from two bases (Cambridge and Norwich), dispatching a physicianparamedic prehospital critical care team in either an H145 helicopter or rapid response vehicle, depending on patient location, weather constraints and time of day (H145 available 07:0023:59 in Cambridge, and 07:00-19:00 in Norwich). During the study period, the Cambridge EAAA base was operational from 07:00 to 01:30 daily, and the Norwich base was operational 24 hours per day 7 days per week with a paramedic-only service (without PHEA capability) from 19:00 through 07:00.

\section{Inclusion criteria}

In order to report outcomes, only patients who were primarily transported by EAAA to the regional neurosciences (and major trauma) centre (Cambridge University Hospitals NHS Foundation Trust, CUH) were included. This allowed cross-reference of injury patterns and outcomes collated by the CUH Trauma Office, and also for retrieval of $\mathrm{PaCO}_{2}$ data from the $\mathrm{CUH}$ electronic medical record. Patients were included if they were attended by EAAA, were $\geq 18$ years old, underwent PHEA, were transported to CUH from scene, had a serious (or more severe) TBI and had complete data. Consistent with recent large data methodology, patients without a $\mathrm{PaCO}_{2}$ measurement within 30 min of hospital arrival were excluded. ${ }^{29}$

\section{Definitions}

PHEA was defined as drug-assisted endotracheal intubation in the prehospital setting. Serious TBI was defined as a retrospectively applied Abbreviated Injury Scale (AIS) score for 'head' $\geq 3$, and serious thoracic injury was defined as an AIS $\geq 3$ for 'thorax'.

\section{Data collection}

The side-stream $\mathrm{ETCO}_{2}$ values and BP (reported as mean arterial pressure, MAP) at hospital handover were obtained from the EAAA electronic medical record that includes a timestamped download from the prehospital monitor (ZOLL X Series Monitor/Defibrillator, ZOLL Medical Corporation of Asahi Kasei Corp., Tokyo). The in-hospital $\mathrm{PaCO}_{2}$ values were obtained from the CUH electronic medical record that includes a time-stamped download of data from an ABG analyzer (COBAS B 221 Blood Gas Analyzer, Roche Diagnostics, Indianapolis, IN, USA). $\mathrm{ETCO}_{2}$ and $\mathrm{PaCO}_{2}$ data were recorded in kilopascal $(\mathrm{kPa})$ units; a conversion of (kPa*7.50062 $=\mathrm{mm} \mathrm{Hg}$ ) has been used to present units of millimetres of mercury alongside $\mathrm{kPa}$.

Demographic, mechanism of injury, injury severity (AIS and Injury Severity Score (ISS)), 30 day mortality and functional outcome (Glasgow Outcome Scale (GOS) score) data were obtained from the CUH Trauma Office records.

\section{Primary outcome}

The primary outcome was to report the $\mathrm{ETCO}_{2}-\mathrm{PaCO}_{2}$ gradient at hospital arrival.

\section{Secondary outcomes}

The secondary outcomes were to report the relationship between the severity of TBI (serious (AIS $=3$ ) and severe $(\mathrm{AIS}=4)$ versus critical (AIS =5)) and $\mathrm{ETCO}_{2}-\mathrm{PaCO}_{2}$ gradient at hospital arrival; to report the effect of a coexisting serious (AIS $\geq 3$ ) thoracic injury on the $\mathrm{ETCO}_{2}-\mathrm{PaCO}_{2}$ gradient at hospital arrival; and to compare the $\mathrm{PaCO}_{2}$ at hospital arrival in patients that received prehospital arterial blood sampling.

\section{Statistical analysis}

Basic demographic, mechanism of injury and injury data have been reported as number (percentage) and mean $( \pm S D)$ or median (IQR) as appropriate. $\mathrm{ETCO}_{2}$ and $\mathrm{PaCO}_{2}$ data have been reported as percentage $(95 \% \mathrm{CI})$ and mean $( \pm \mathrm{SD})$. Comparisons of unpaired, normally distributed, continuous variables were undertaken with a two-tailed unpaired t-test (with Welch's correction if samples had unequal deviations).

Fisher's exact test has been used to compare proportions. Linear regressions have been performed to test for correlation and are reported as $\mathrm{R}$-squared $\left(\mathrm{R}^{2}\right)$ with gradient of the slope $(m)$. A Bland-Altman plot has been used to test for agreement between paired $\mathrm{ETCO}_{2}$ and $\mathrm{PaCO}_{2}$ data, and has been reported as bias $(95 \% \mathrm{CI})$ with upper and lower limits of agreement.

Statistical analyses were performed using the $\mathrm{R}$ statistical programming language (R Core Team (2018); R: A language and environment for statistical computing ( $\mathrm{R}$ Foundation for Statistical Computing, Vienna, Austria); significance was predefined at $<0.05$ and no corrections were made for multiple comparisons.

\section{Patient and public involvement}

Patients or the public were not involved in the design, conduct, reporting or dissemination plans of our research.

\section{RESULTS}

\section{Demographics and injury}

107 patients were eligible for inclusion. Sixty-seven patients did not receive a $\mathrm{PaCO}_{2}$ sample within $30 \mathrm{~min}$ of hospital arrival and were therefore excluded. Forty patients had complete data and were included in the final analysis; per protocol. The median age was $45(23-63)$ years, $24(60.0 \%)$ were male. The most prevalent mechanism of injury was road traffic collision, $n=22$ 


\begin{tabular}{|c|c|}
\hline & $\mathrm{N}(\%)$ or median (IQR) \\
\hline \multicolumn{2}{|l|}{ Gender } \\
\hline Male & $24(60.0)$ \\
\hline Female & $16(40.0)$ \\
\hline \multicolumn{2}{|l|}{ Age } \\
\hline Total & $45(23-63)$ \\
\hline Male & $34(22-62)$ \\
\hline Female & $50(33-66)$ \\
\hline \multicolumn{2}{|l|}{ Mechanism of injury } \\
\hline Road traffic collision & $22(55.0)$ \\
\hline Fall from height & $17(42.5)$ \\
\hline Crush injury & $1(2.5)$ \\
\hline \multicolumn{2}{|l|}{ Injury Severity Score } \\
\hline ISS >15 & 39 (97.5) \\
\hline ISS >25 & $33(82.5)$ \\
\hline \multicolumn{2}{|l|}{ 'Head' Abbreviated Injury Severity } \\
\hline Serious TBI (AIS 3) & $8(20.0)$ \\
\hline Severe TBI (AIS 4) & $8(20.0)$ \\
\hline Critical TBI (AIS 5) & $24(60.0)$ \\
\hline \multicolumn{2}{|l|}{ Prehospital $\mathrm{PaCO}_{2}$ measurement } \\
\hline Yes & $7(17.5)$ \\
\hline No & $33(82.5)$ \\
\hline \multicolumn{2}{|l|}{ Patient outcome at 30 days } \\
\hline Alive & $28(70.0)$ \\
\hline Dead & $12(30.0)$ \\
\hline Glasgow Outcome Score $\leq 3$ & $24(60.0)$ \\
\hline Glasgow Outcome Score $\geq 4$ & $16(40.0)$ \\
\hline
\end{tabular}

AIS, Abbreviated Injury Scale score; ISS, Injury Severity Score; $\mathrm{PaCO}_{2}$, partial pressure of arterial carbon dioxide; TBI, traumatic brain injury.

(55.0\%). The median ISS was $31(26-38)$, and $97.5 \%$ of the cohort had an ISS $\geq 15$. The mean hospital arrival MAP was 93.7 $( \pm 24.4) \mathrm{mm} \mathrm{Hg}$. Overall, 30 day mortality was $30.0 \%$ (95\% CI 16.6 to 47.9 ), and all survivors had a GOS $\geq 3$ (severe disability or better), table 1 .

\section{$\mathrm{ETCO}_{2}-\mathrm{PaCO}_{2}$}

Overall, the mean $\mathrm{ETCO}_{2}$ and $\mathrm{PaCO}_{2}$ were $4.1( \pm 0.7) \mathrm{kPa}$ $(30.7 \mathrm{~mm} \mathrm{Hg})$ and $5.8( \pm 1.1) \mathrm{kPa}(43.3 \mathrm{~mm} \mathrm{Hg})$, respectively. In $38 / 40$ (95.0\%, 95\% CI 83.5 to 98.6) patients, the $\mathrm{PaCO}_{2}$ was more than $0.5 \mathrm{kPa}(3.8 \mathrm{~mm} \mathrm{Hg})$ higher than the $\mathrm{ETCO}_{2}$. No patients were hypocapnic $\left(\mathrm{PaCO}_{2}\right.$ lower than $4.0 \mathrm{kPa}(30.0 \mathrm{~mm}$ $\mathrm{Hg})$ ) and there was moderate correlation between $\mathrm{ETCO}_{2}$ and $\mathrm{PaCO}_{2}\left(\mathrm{R}^{2}=0.23, m=0.72, \mathrm{p}=0.002\right)$, figure 1 .

\section{Primary outcome}

The mean $\mathrm{ETCO}_{2}-\mathrm{PaCO}_{2}$ gradient was $1.7( \pm 1.0) \mathrm{kPa}(12.8 \mathrm{~mm}$ $\mathrm{Hg}$ ), figure 1 . The Bland-Altman analysis looking at the difference between $\mathrm{PaCO}_{2}$ and ETCO showed the bias to be 1.7 (95\% CI 1.4 to 2.0$) \mathrm{kPa}$ with upper and lower limits of agreement of $3.6(95 \%$ CI 3.0 to 4.1$) \mathrm{kPa}$ and $-0.2(95 \% \mathrm{CI}-0.8$ to 0.3$) \mathrm{kPa}$, respectively, figure 2 .

\section{Secondary outcomes}

Severity of TBI

Patients with a critical TBI (AIS of 5), $\mathrm{n}=24(60.0 \%)$ had a comparable mean $\mathrm{ETCO}_{2}-\mathrm{PaCO}_{2}$ gradient compared with those with a serious or severe (AIS $=3$ or 4$)$ injury-1.8 $( \pm 1.1) \mathrm{kPa}$ $(13.5 \mathrm{~mm} \mathrm{Hg})$ and $1.5( \pm 0.7) \mathrm{kPa}(11.2 \mathrm{~mm} \mathrm{Hg})$, respectively,

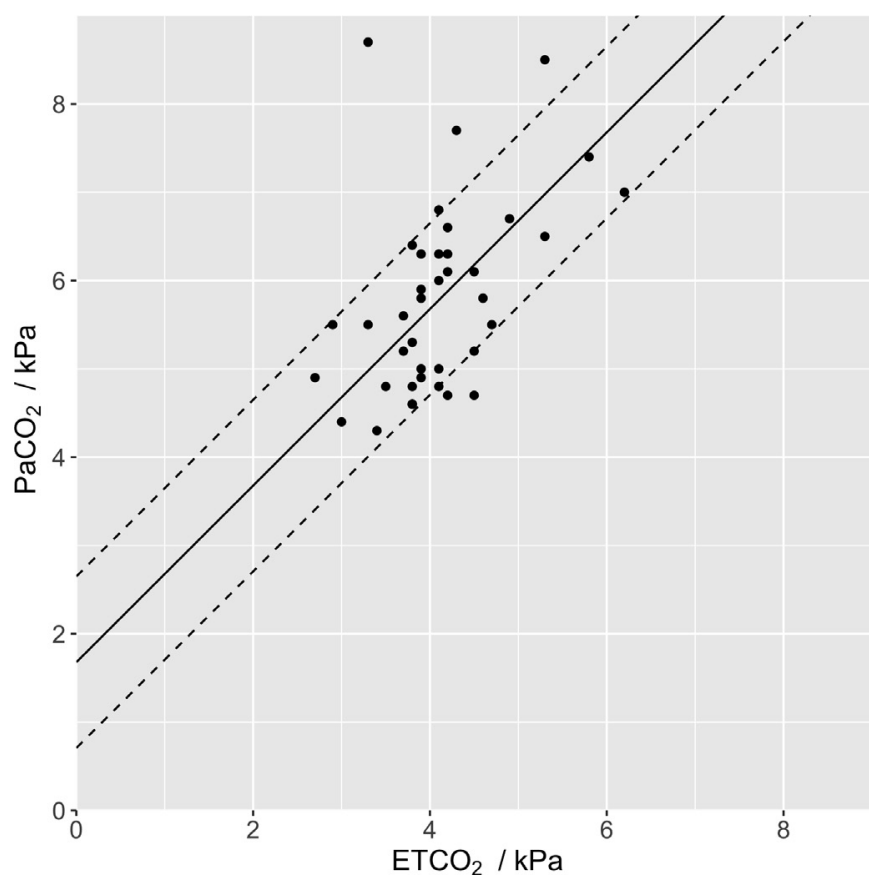

Figure 1 Scatter plot of the relationship between $\mathrm{ETCO}_{2}$ and $\mathrm{PaCO}_{2}$ at hospital arrival. $1.0 \mathrm{kPa}=7.50062 \mathrm{~mm} \mathrm{Hg}$. The $\mathrm{ETCO}_{2}-\mathrm{PaCO}_{2}$ gradient was $1.7( \pm 1.0) \mathrm{kPa}(12.8 \mathrm{~mm} \mathrm{Hg})$. The mean is plotted as a single line and SD as dashed lines. $\mathrm{ETCO}_{2}$, end-tidal carbon dioxide; $\mathrm{PaCO}_{2}$, arterial partial pressure of carbon dioxide.

$\mathrm{p}=0.29$. Both of these groups (AIS $=5$ and AIS $=3$ or 4 ) demonstrated a moderate correlation $\left(\mathrm{R}^{2}=0.22, m=0.64, \mathrm{p}=0.02\right.$ and $\mathrm{R}^{2}=0.31, m=1.31, \mathrm{p}=0.03$, respectively).

\section{Thoracic injury}

$22 / 40(55.0 \%)$ patients had a serious thoracic injury. The mean $\mathrm{ETCO}_{2}-\mathrm{PaCO}_{2}$ gradient in this subgroup was $2.0( \pm 1.1) \mathrm{kPa}$ $(15.1 \mathrm{~mm} \mathrm{Hg})$, significantly higher than the $18 / 40$ patients without a serious thoracic injury-1.3 $( \pm 0.5) \mathrm{kPa}(9.5 \mathrm{~mm} \mathrm{Hg})$, $\mathrm{p}=0.01$. There was no significant correlation in the thoracic injury subgroup $\left(\mathrm{R}^{2}=0.13, m=0.54, \mathrm{p}=0.10\right)$, but there was a significant correlation in the group without serious thoracic injury $\left(\mathrm{R}^{2}=0.51, m=0.78, \mathrm{p}<0.001\right)$. There was no significant difference in mean MAP at hospital arrival between patients with and without a serious thoracic injury-91.9 $( \pm 25.3) \mathrm{mm}$ $\mathrm{Hg}$ and $95.9( \pm 23.7) \mathrm{mm} \mathrm{Hg}$, respectively, $\mathrm{p}=0.60$.

\section{Prehospital $\mathrm{PaCO}_{2}$ measurement}

Seven $(17.5 \%)$ patients underwent prehospital measurement of $\mathrm{PaCO}_{2}$, using the iSTAT (Abbott Laboratories, Illinois, USA) point-of-care ABG (POC-ABG) analyzer. The POC-ABG group had a significantly lower, and more appropriate hospital arrival $\mathrm{PaCO}_{2}$, compared with the no-ABG group-4.7 $( \pm 0.2) \mathrm{kPa}$ $(35.1 \mathrm{~mm} \mathrm{Hg})$ versus $6.0( \pm 1.1) \mathrm{kPa}(45.0 \mathrm{~mm} \mathrm{Hg})$, respectively, $\mathrm{p}=0.7 \times 10^{-7}$.

\section{DISCUSSION}

This study has demonstrated that patients with an AIS $\geq 3$ TBI have a larger $\mathrm{ETCO}_{2}-\mathrm{PaCO}_{2}$ gradient at hospital arrival than previously reported. The severity of TBI was not significantly associated with the $\mathrm{ETCO}_{2}-\mathrm{PaCO}_{2}$ gradient. However, the presence of a coexisting serious thoracic injury was associated with a significantly larger $\mathrm{ETCO}_{2}-\mathrm{PaCO}_{2}$ gradient, which is manifest as an apparent bias in the Bland-Altman plot of figure 2. In the 


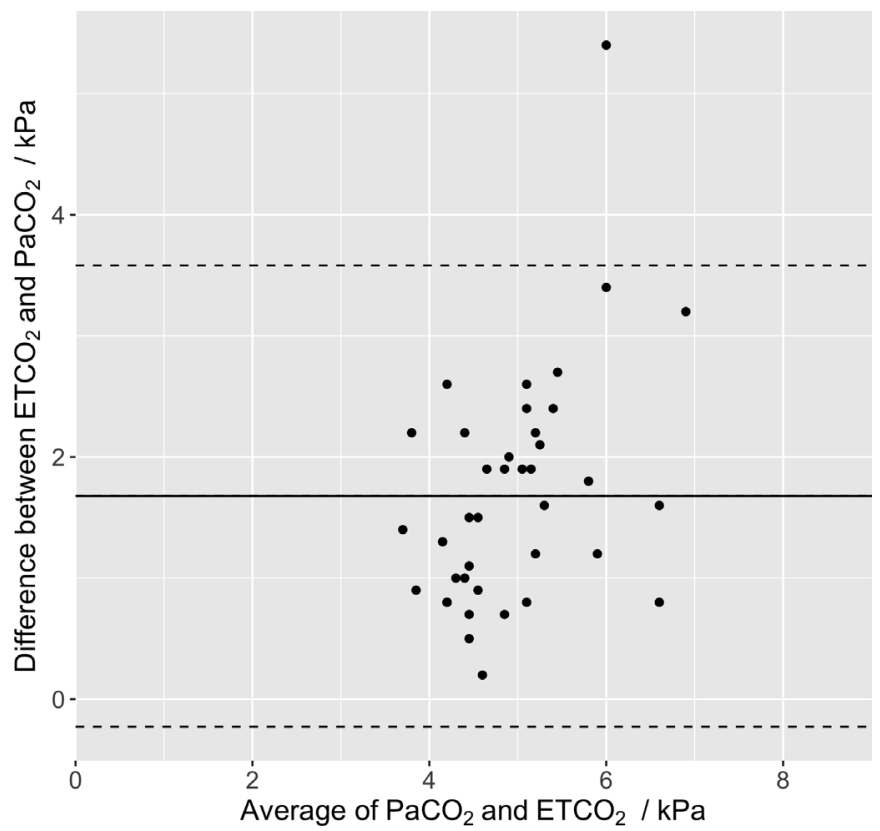

Figure 2 Bland-Altman plot of the agreement between $\mathrm{ETCO}_{2}$ and $\mathrm{PaCO}_{2}$ at hospital arrival. $1.0 \mathrm{kPa}=7.50062 \mathrm{~mm} \mathrm{Hg}$. The bias is $1.7(95 \%$ $\mathrm{Cl} 1.4$ to 2.0$) \mathrm{kPa}$ with upper and lower limits of agreement of 3.6 ( $95 \% \mathrm{Cl} 3.0$ to 4.1$) \mathrm{kPa}$ and $-0.2(95 \% \mathrm{Cl}-0.8$ to 0.3$) \mathrm{kPa}$, respectively. The bias is plotted as a single line, and the upper and lower limits of agreement as dashed lines. $\mathrm{ETCO}_{2}$, end-tidal carbon dioxide; $\mathrm{PaCO}_{2}$, arterial partial pressure of carbon dioxide.

serious thoracic injury cohort, there was no evidence of correlation between $\mathrm{ETCO}_{2}$ and $\mathrm{PaCO}_{2}$. All patients who underwent prehospital $\mathrm{PaCO}_{2}$ measurement had a low-normal $\mathrm{PaCO}_{2}$ at hospital arrival.

$\mathrm{PaCO}_{2}$ is a major determinant of CBF through its effects on cerebral vascular tone. Ventilatory control is crucial to the management of $\mathrm{TBI}^{20}$ Even modest hypercapnia may result in substantial increases in ICP when intracranial compliance is poor. $^{21}$ Conversely, even modest hyperventilation has been shown to lead to dangerous cerebral ischaemia, ${ }^{22}$ and this may be of particular importance in the first hours after TBI when hypoperfusion is a dominant pathology. ${ }^{23}$

Current guidance recommends an $\mathrm{ETCO}_{2}$ of $4.0-4.5 \mathrm{kPa}$ $(30.0-33.8 \mathrm{~mm} \mathrm{Hg})$ as a surrogate for a low-normal $\mathrm{PaCO}_{2}{ }^{7}$ This guidance relies on the assumption that the $\mathrm{ETCO}_{2}-\mathrm{PaCO}_{2}$ gradient is approximately $0.5 \mathrm{kPa}(3.8 \mathrm{~mm} \mathrm{Hg})$, and is predominantly extrapolated from healthy individuals. In this study, the mean hospital arrival ETCO 2 was $4.1( \pm 0.7) \mathrm{kPa}(30.7 \mathrm{~mm}$ $\mathrm{Hg}$ ), which suggests that the prehospital providers adhered closely to the extant guidelines. Despite this, the mean $\mathrm{PaCO}_{2}$ was $5.8( \pm 1.1) \mathrm{kPa}(43.3 \mathrm{~mm} \mathrm{Hg})$ - far in excess of the target of $4.5-5.0 \mathrm{kPa},{ }^{24}$ owing to a mean $\mathrm{ETCO}_{2}-\mathrm{PaCO}_{2}$ gradient of 1.7 $( \pm 1.0) \mathrm{kPa}(12.8 \mathrm{~mm} \mathrm{Hg})$. The result of this is that when relying on $\mathrm{ETCO}_{2}$ as a surrogate, providers may not achieve an optimal prehospital $\mathrm{PaCO}_{2}$.

The arterial-alveolar $\mathrm{CO}_{2}$ gradient is determined by the ratio of physiological dead space and tidal volume. Since 2000 and the publication of the ARDSNet study, ventilatory practice has shifted towards the use of lower tidal volumes. ${ }^{25}$ Therefore, in contemporary practice the $\mathrm{ETCO}_{2}-\mathrm{PaCO}_{2}$ gradient would be expected to be larger because the dead space is more appreciable, and it may be that the target $\mathrm{ETCO}_{2}$ needs to be reconsidered. It is tempting to advocate a lower prehospital $\mathrm{ETCO}_{2}$ - perhaps
$2.8-3.3 \mathrm{kPa}(21.0-24.8 \mathrm{~mm} \mathrm{Hg})$ in patients suspected of having an AIS $\geq 3$ TBI (assuming a gradient of $1.7 \mathrm{kPa}(12.8 \mathrm{~mm} \mathrm{Hg})$ ), particularly in the setting of coexisting thoracic injury. However, this strategy may risk hypocapnia $\left(\mathrm{PaCO}_{2}<4.0 \mathrm{kPa}(30.0 \mathrm{~mm}\right.$ $\mathrm{Hg})$ ), which in the setting of a very high ICP may be of benefit via hypocapnic arterial vasoconstriction, ${ }^{21}$ but in the more likely prehospital clinical scenario ( $<24$ hours after TBI) of normal ICP, may lead to severe cerebral ischaemia and worse outcomes. ${ }^{26}$

There was only moderate correlation between $\mathrm{ETCO}_{2}$ and $\mathrm{PaCO}_{2}$; statistically, only $23 \%$ of the variance $\left(\mathrm{R}^{2}\right.$, the coefficient of determination) observed in $\mathrm{ETCO}_{2}$ can be explained by the $\mathrm{PaCO}_{2}$. There was no ETCO $-\mathrm{PaCO}_{2}$ gradient correlation in the subgroup with an AIS $\geq 3$ thoracic injury. We presume that this is owing to the effect of heterogeneous physiological dead space (caused by the thoracic injury) on the arterial-alveolar $\mathrm{CO}_{2}$ gradient. Therefore, in those without an AIS $\geq 3$ thoracic injury the $\mathrm{ETCO}_{2}-\mathrm{PaCO}_{2}$ gradient correlation was better; statistically $51 \%$ of the variance observed in $\mathrm{ETCO}_{2}$ can be explained by $\mathrm{PaCO}_{2}$. In order to ensure that the increased gradient observed in the AIS $\geq 3$ thoracic injury group was not simply due to a lower systemic perfusion compared with the group without serious thoracic injury, MAP at hospital arrival was reported between the two groups. Although there is a known relationship between tissue perfusion and $\mathrm{ETCO}_{2},{ }^{11}$ there was no difference between the MAP (used as a surrogate for perfusion) at hospital arrival between those with and without an AIS $\geq 3$ thoracic injury. We think that this strengthens the theory that thoracic injury increases the physiological dead space. It is unclear from these data what variable(s) make up the remaining $49 \%$ of variance observed. We acknowledge the transfer from a prehospital to an in-hospital ventilator may be one factor in this. However, EAAA and CUH use identical ventilators (Dräger Oxylog 3000, Drägerwerk AG \&Co., Lübeck, Germany), and it is standard practice to commence in-hospital ventilation using the prehospital settings.

It is not necessarily surprising that in this small sample with significant variance we were not able to demonstrate a significant difference between the severity of TBI (as measured by AIS) and the $\mathrm{ETCO}_{2}-\mathrm{PaCO}_{2}$ gradient, and it is possible that this represents a type- 2 error. Previous work has demonstrated an increased gradient in more severe injury (higher ISS), but has not examined head or thoracic injury specifically, ${ }^{16}$ and has shown an increased mortality in 'abnormal' hospital-arrival $\mathrm{ETCO}_{2}{ }^{27}$ In the subgroup of patients with a serious thoracic injury, the ETCO $-\mathrm{PaCO}_{2}$ gradient was significantly higher than those without a serious thoracic injury, further compounding the inaccuracy in estimating $\mathrm{PaCO}_{2}$ from $\mathrm{ETCO}_{2}$ in the severely injured trauma patient. The patients in our study were all primarily transported to the regional neurosciences (and major trauma) centre by a prehospital critical care team. Therefore, it is possible that we are missing data from both ends of the severity spectrum: patients with a lesser injury and those with a more immediate requirement for in-hospital resuscitation may have been initially transported to a local trauma unit hospital. Our limited analysis of the effect of severity of TBI on gradient demonstrated a non-significant trend of increasing gradient with increasing TBI severity. However, the pragmatic clinical benefits of knowing if severity of TBI affects the $\mathrm{ETCO}_{2}-\mathrm{PaCO}_{2}$ gradient is minimal-without good evidence of strong correlation between $\mathrm{ETCO}_{2}$ and $\mathrm{PaCO}_{2}$, the provider cannot rely on $\mathrm{ETCO}_{2}$ as a surrogate.

Inadvertent hypocapnia is an important factor in avoidable neuronal injury following TBI via a reduction in CBF and an increase in cerebral oxygen consumption. ${ }^{22}$ While we have 
concentrated on hypercapnia in this study, it is encouraging to see that even in the presence of significant heterogeneity in $\mathrm{ETCO}_{2}-\mathrm{PaCO}_{2}$ gradient in this population, no patients were hypocapnic on arrival to hospital using the extant guidelines.

Even from this small sample of patients it is evident that using the $\mathrm{ETCO}_{2}$ as a surrogate for $\mathrm{PaCO}_{2}$ following TBI is a blunt tool. There is a larger than previously reported mean $\mathrm{ETCO}_{2}-$ $\mathrm{PaCO}_{2}$ gradient and only moderate correlation. The practice of low tidal volume ventilation may necessitate a reconsideration of the expected $\mathrm{ETCO}_{2}-\mathrm{PaCO}_{2}$ gradient, but the lack of correlation in those with a concomitant thoracic injury means that significant inaccuracy in using ETCO 2 as a surrogate for $\mathrm{PaCO}_{2}$ would likely continue. Numerous other surrogates have been used for $\mathrm{PaCO}_{2}$, including transcutaneous $\mathrm{CO}_{2}$ monitoring and capillary blood gas analysis. ${ }^{28} 29$ However, at present, an ABG sample is the only reliable way to obtain an accurate $\mathrm{PaCO}_{2}$ with which to guide ventilation in TBI. The advancement in technology and production of smaller, portable analyzers allow providers to accurately determine $\mathrm{PaCO}_{2}$ prehospital and in other resourcelimited settings. ${ }^{3031} \mathrm{~A}$ small number of patients in our study underwent prehospital measurement of $\mathrm{PaCO}_{2}$ using a POC analyzer. There was evidence during chart review of these seven patients that the providers made alterations to the ventilation strategy after $\mathrm{PaCO}_{2}$ analysis; they all demonstrated a favourable hospital arrival $\mathrm{PaCO}_{2}$.

This study used data from a single prehospital critical care service and a single regional neurosciences centre, and as such the results may not be widely applicable. In order to increase the number of patients in this study, we included patients who had an ABG up to $30 \mathrm{~min}$ after hospital arrival. It is therefore possible that a proportion of the gradient variance observed was due to changes in ventilation strategy during this period, but standard clinical practice means this should be clinically negligible. The availability of these data very early in this disease process is extremely limited, resulting in a small sample size. It is possible that non-significant findings are due to a lack of statistical power.

\section{CONCLUSION}

There is only moderate correlation of $\mathrm{ETCO}_{2}$ and $\mathrm{PaCO}_{2}$ at hospital arrival in patients with serious TBI. The mean $\mathrm{ETCO}_{2}-$ $\mathrm{PaCO}_{2}$ gradient was $1.7( \pm 1.0) \mathrm{kPa}(12.8 \mathrm{~mm} \mathrm{Hg})$-greater than previously reported. Lower $\mathrm{ETCO}_{2}$ targets than previously recommended may be safe and appropriate, particularly in the presence of thoracic injury. There may be a role for prehospital $\mathrm{PaCO}_{2}$ measurement.

\section{Twitter Ed Benjamin Graham Barnard @edbarn}

Acknowledgements We acknowledge the assistance of Assiah Mahmood and Jacques Bowman of the CUH Trauma Office in compiling the original data.

Contributors The study was conceived by JP, DDS and EBGB. The study permissions were obtained by EBGB and AW. Data acquisition was undertaken by JP and DDS. $D D S, A E$ and $E B G B$ interpreted the data. The manuscript was prepared by JP and EBGB. Critical revisions were done by $A E, A W$ and EBGB. All authors reviewed and approved the final draft.

Funding The authors have not declared a specific grant for this research from any funding agency in the public, commercial or not-for-profit sectors.

\section{Competing interests None declared.}

Patient and public involvement Patients and/or the public were not involved in the design, or conduct, or reporting or dissemination plans of this research.

Patient consent for publication Not required.

Ethics approval This service evaluation was registered with both EAAA and CUH. Local agreement for the use of anonymised data from the EAAA electronic medical record was granted through extant data use protocols. Anonymised, linked data were obtained from the CUH Trauma Office, and $\mathrm{PaCO}_{2}$ values obtained from the CUH electronic medical record. Ethical review was undertaken by the Cambridge University Hospitals NHS Foundation Trust Safety and Quality Support Department (reference: PRN7866).

Provenance and peer review Not commissioned; externally peer reviewed. Data availability statement Data are available upon reasonable request.

Open access This is an open access article distributed in accordance with the Creative Commons Attribution Non Commercial (CC BY-NC 4.0) license, which permits others to distribute, remix, adapt, build upon this work non-commercially, and license their derivative works on different terms, provided the original work is properly cited, appropriate credit is given, any changes made indicated, and the use is non-commercial. See: http://creativecommons.org/licenses/by-nc/4.0/.

\section{ORCID iDs}

James Price http://orcid.org/0000-0002-9643-692X

Ari Ercole http://orcid.org/0000-0001-8350-8093

Ed Benjamin Graham Barnard http://orcid.org/0000-0002-5187-1952

\section{REFERENCES}

1 Dewan MC, Rattani A, Gupta S, et al. Estimating the global incidence of traumatic brain injury. J Neurosurg 2018:1-18.

2 Alali AS, Fowler RA, Mainprize TG, et al. Intracranial pressure monitoring in severe traumatic brain injury: results from the American College of surgeons trauma quality improvement program. J Neurotrauma 2013;30:1737-46.

3 Lockey DJ, Healey B, Crewdson $\mathrm{K}$, et al. Advanced airway management is necessary in prehospital trauma patients. Br J Anaesth 2015;114:657-62.

4 Burgess MR, Crewdson K, Lockey DJ, et al. Prehospital emergency anaesthesia: an updated survey of UK practice with emphasis on the role of standardisation and checklists. Emerg Med J 2018;35:532-7.

5 Lawrence T, Helmy A, Bouamra O, et al. Traumatic brain injury in England and Wales: prospective audit of epidemiology, complications and standardised mortality. BMJ Open 2016;6:e012197.

6 Walrath BD, Harper S, Barnard E, et al. Airway management for trauma patients. Mil Med 2018;183:29-31.

7 Lockey DJ, Crewdson K, Davies G, et al. AAGBI: safer pre-hospital anaesthesia 2017 Anaesthesia 2017;72:379-90.

8 Badjatia N, Carney N, Crocco TJ, et al. Guidelines for prehospital management of traumatic brain injury 2nd edition. Prehosp Emerg Care 2008;12 Suppl 1:S1-52.

9 Fletcher $\mathrm{R}$, Jonson $\mathrm{B}$. Deadspace and the single breath test for carbon dioxide during anaesthesia and artificial ventilation. Effects of tidal volume and frequency of respiration. Br J Anaesth 1984;56:109-19.

10 Razi E, Moosavi GA, Omidi K, et al. Correlation of end-tidal carbon dioxide with arterial carbon dioxide in mechanically ventilated patients. Arch Trauma Res 2012;1:58-62.

11 Lee S-W, Hong Y-S, Han C, et al. Concordance of end-tidal carbon dioxide and arterial carbon dioxide in severe traumatic brain injury. J Trauma 2009;67:526-30.

12 Gaur P, Harde M, Gujjar P, et al. A study of partial pressure of arterial carbon dioxide and end-tidal carbon dioxide correlation in intraoperative and postoperative period in neurosurgical patients. Asian J Neurosurg 2017;12:475-82.

13 Adams H, Donnelly J, Czosnyka M, et al. Temporal profile of intracranial pressure and cerebrovascular reactivity in severe traumatic brain injury and association with fatal outcome: an observational study. PLoS Med 2017;14:e1002353.

14 Rangel-Castilla L, Rangel-Castillo L, Gopinath S, et al. Management of intracranial hypertension. Neurol Clin 2008;26:521-41.

15 Feldmann E, Skolnick BE. Cerebral hemodynamics, autoregulation, and blood pressure management. J Stroke Cerebrovasc Dis 1999;8:176-82.

16 Cooper CJ, Kraatz JJ, Kubiak DS, et al. Utility of prehospital quantitative end tidal C02? Prehosp Disaster Med 2013;28:87-93

17 Belpomme V, Ricard-Hibon A, Devoir C, et al. Correlation of arterial PCO2 and PETCO2 in prehospital controlled ventilation. Am J Emerg Med 2005;23:852-9.

18 Warner KJ, Cuschieri J, Garland B, et al. The utility of early end-tidal capnography in monitoring ventilation status after severe injury. J Trauma 2009;66:26-31.

19 Yang J-T, Erickson SL, Killien EY, et al. Agreement between arterial carbon dioxide levels with end-tidal carbon dioxide levels and associated factors in children hospitalized with traumatic brain injury. JAMA Netw Open 2019;2:e199448.

20 Menon DK, Ercole A. Chapter 14 critical care management of traumatic brain injury. Handb Clin Neurology 2017;140:239-74.

21 Steiner LA, Balestreri M, Johnston AJ, et al. Predicting the response of intracrania pressure to moderate hyperventilation. Acta Neurochir 2005; 147:477-83.

22 Coles JP, Fryer TD, Coleman MR, et al. Hyperventilation following head injury: effect on ischemic burden and cerebral oxidative metabolism. Crit Care Med 2007;35:568-78.

23 Launey Y, Fryer TD, Hong YT, et al. Spatial and temporal pattern of ischemia and abnormal vascular function following traumatic brain injury. JAMA Neurol 2020;77:339-49.

24 Nathanson MH, Andrzejowski J, Dinsmore J, et al. Guidelines for safe transfer of the brain-injured patient: trauma and stroke, 2019. Anaesthesia 2020;75:234-46. 
25 Acute Respiratory Distress Syndrome Network, Brower RG, Matthay MA, et al. Ventilation with lower tidal volumes as compared with traditional tidal volumes for acute lung injury and the acute respiratory distress syndrome. N Engl J Med 2000;342:1301-8.

26 Muizelaar JP, Marmarou A, Ward JD, et al. Adverse effects of prolonged hyperventilation in patients with severe head injury: a randomized clinical trial. $J$ Neurosurg 1991;75:731-9.

27 Holmes J, Peng J, Bair A. Abnormal end-tidal carbon dioxide levels on emergency department arrival in adult and pediatric intubated patients. Prehosp Emerg Care $2012 ; 16: 210-6$
28 Binder $\mathrm{N}$, Atherton $\mathrm{H}$, Thorkelsson T, et al. Measurement of transcutaneous carbon dioxide in low birthweight infants during the first two weeks of life. Am J Perinatol 1994:11:237-41.

29 Zavorsky GS, Cao J, Mayo NE, et al. Arterial versus capillary blood gases: a metaanalysis. Respir Physiol Neurobiol 2007;155:268-79.

30 Prause G, Ratzenhofer-Komenda B, Offner A, et al. Prehospital point of care testing of blood gases and electrolytes - an evaluation of IRMA. Crit Care 1997;1:79.

31 Barnard E, Baladurai S, Badh T, et al. Challenges of managing toxic alcohol poisoning in a resource-limited setting. J R Army Med Corps 2014;160:245-50. 